\title{
BMJ Open Prevalence and risk factors of myopic maculopathy: a cross-sectional study in Han and Uygur adults in Xinjiang, China
}

\author{
Ting Chen (D) , ${ }^{1}$ Jin Ma, ${ }^{2}$ Guang-Liang Shan, ${ }^{3}$ Lize Pa, ${ }^{4}$ Lin Ding, ${ }^{5}$ Li Pan, ${ }^{3}$ \\ Limujiang Ke, ${ }^{5}$ Hebuli Mu, ${ }^{4}$ Senjiang Ya, ${ }^{4}$ Ning Tao, ${ }^{6}$ Fen Dong (D) ${ }^{3}$ Ke Wang, ${ }^{3}$ \\ Yong Zhong (iD) ${ }^{2}$
}

To cite: Chen T, Ma J, Shan G$\mathrm{L}$, et al. Prevalence and risk factors of myopic maculopathy: a cross-sectional study in Han and Uygur adults in Xinjiang, China. BMJ Open 2020;10:e034775. doi:10.1136/ bmjopen-2019-034775

- Prepublication history and additional material for this paper are available online. To view these files, please visit the journal online (http://dx.doi. org/10.1136/bmjopen-2019034775).

Received 04 0ctober 2019 Revised 28 June 2020 Accepted 07 August 2020
Check for updates

(C) Author(s) (or their employer(s)) 2020. Re-use permitted under CC BY-NC. No commercial re-use. See rights and permissions. Published by BMJ.

For numbered affiliations see end of article.

Correspondence to

Dr Yong Zhong;

yzhong_eye@163.com

\section{ABSTRACT}

Objectives To estimate the prevalence, ethnic differences and associated risk factors of myopic maculopathy in Han and Uygur adults in Xinjiang, China.

Design and setting $A$ cross-sectional study with multistage, stratified cluster sampling method was conducted in Xinjiang, China.

Participants A total of 4023 Han and Uygur participants aged 40 years and older were eligible for the study. Outcome measures The association between myopic maculopathy and its risk factors was screened using the generalised estimating equation (GEE) model. We also investigated whether ethnic differences exist between Han and Uygur populations affected by myopic maculopathy. Myopic maculopathy was defined in accordance with International Photographic Classification and Grading System for Myopic Maculopathy.

Results A total of 3044 subjects (5946 eyes) were included in our study (1736 Han and 1308 Uygur individuals). The participants consisted of 1256 (41.3\%) men and 1788 (58.7\%) women. The average age was $52.2 \pm 9.4$ years, and the mean spherical equivalent (SE) was $-0.18 \pm 2.31$ dioptre (D). Myopic maculopathy was detected in 198 eyes of 138 participants. The age-adjusted prevalence of myopic maculopathy reached 5.8\% (95\% Cl 4.8 to 6.8). In the GEE model, myopic maculopathy was significantly associated with old age (per year; OR: $1.16 ; 95 \% \mathrm{Cl} 1.13$ to $1.19 ; \mathrm{p}<0.001$ ) and myopic SE (per $-1 \mathrm{D} ; 0 \mathrm{R}: 1.48 ; 95 \% \mathrm{Cl} 1.40$ to $1.56 ; \mathrm{p}<0.001$ ). No ethnic differences were detected between Han (98, $5.7 \%$ ) and Uygur population (40,3.1\%) in terms of the prevalence of myopic maculopathy $(\mathrm{OR}=0.89 ; 95 \% \mathrm{Cl} 0.53$ to 1.48; $p=0.64)$. Neither urbanisation $(p=0.38)$ nor the level of education $(p=0.92)$ was associated with myopic maculopathy.

Conclusions A high age-adjusted prevalence of myopic maculopathy was observed in Han and Uygur populations in Xinjiang, China. Old age and high degree of myopic refraction were independent risk factors for myopic maculopathy. No ethnic differences were detected in Han and Uygur populations affected by myopic maculopathy.

\section{Strengths and limitations of this study}

- The study reported the prevalence of myopic maculopathy and analysed the ethnic differences in myopic maculopathy between Han and Uygur citizens living in the same area.

- Direct comparison of studies on myopic maculopathy using the newly developed classification, that is, International Photographic Classification and Grading System for Myopic Maculopathy, was feasible.

- The association between axial length and myopic maculopathy was not investigated in this study.

- Staphyloma was not evaluated as a sign of myopic maculopathy, which possibly led to the underestimation of the prevalence of myopic maculopathy, given the availability of non-stereoscopic fundus photographs.

- The younger age, less women and more higher education levels of participants compared with the nonparticipants (non-response bias) might have affected the prevalence estimate of myopic maculopathy.

\section{INTRODUCTION}

High myopia (spherical equivalent (SE) less than -6 dioptres (D)) is one of the common causes of visual impairment worldwide, especially in East Asia. The reported prevalence of high myopia ranges from $0.9 \%$ to $5.6 \%$ among East Asians aged more than 30 years old. ${ }^{1-4}$ People with high myopia suffer from an increased risk of ocular diseases, such as myopic maculopathy, glaucoma and retinal detachment. ${ }^{56}$ The main changes in high myopia include the elongation of axial length and deformation of the eyeball, resulting in a range of retinal and choroidal lesions. The lesions located in the posterior pole are termed myopic maculopathy, which often affects middle-aged and working people. ${ }^{78}$ Myopic maculopathy, which is the second leading cause of blindness in China ${ }^{9}$ 
and the third in Japan, ${ }^{10}$ is currently one of the major causes of legal blindness worldwide. Although studies have reported the prevalence of myopia maculopathy, the results cannot be compared directly given the inconsistent definitions of myopic maculopathy. Ohno-Matsui et $a l^{11}$ proposed the International Photographic Classification and Grading System for Myopic Maculopathy (META-PM) in 2015 for the direct comparison of myopia maculopathy results. However, studies on myopic maculopathy based on META-PM classification are limited. Moreover, although ethnic differences in myopic maculopathy have been proposed in several studies, ${ }^{12}{ }^{13}$ no research has investigated such topic to date.

In the present study, we aimed to estimate the prevalence and associated risk factors of myopic maculopathy in Xinjiang using the META-PM classification. The study area is located in northwest region of China, occupies the largest land area at approximately 1.66 million $\mathrm{km}^{2}$, and has an average altitude of $900 \mathrm{~m}$. Xinjiang is also a multiethnic populated area, including Uygur, Han and Kazak populations, with the Uygur population accounting for approximately one-half of the total population. No study has assessed the ethnic differences in myopic maculopathy in the same geographical location. Thus, we also explored whether ethnic differences exist in the distribution of myopic maculopathy in the two major ethnic groups (ie, Han and Uygur populations) living in the same location.

\section{METHODS}

\section{Study population}

Our study is a part of the China National Health Survey and was performed with a multistage stratified cluster sampling method. ${ }^{14}$ The study was conducted in Xinjiang in 2013. The selection of cities and counties was based on the degree of urbanisation, economic development status based on gross domestic product and the distribution of local predominant minority ethnic populations. The first non-randomised sampling stage involved the selection of cities in Xinjiang (ie, large cities (Urumqi), midsize cities (Wusu and Karamay City) and counties (Hami and Toksun)). The second randomised sampling stage selected districts from cities and rural townships from counties. The third stage selected communities from districts in urban areas and villages from townships in rural areas. The final sampling stage involved the recruitment of participants in the study.

\section{Inclusion and exclusion criteria}

The inclusion criteria in our study were as follows: (1) residents who have been living in the selected areas for more than 1 year, (2) age of 40 years and older, (3) individuals with both parents originating from Han or Uygur defined as the corresponding ethnicity and (4) completely answered questionnaire. The exclusion criteria were as follows: (1) subjects who did not participate in ophthalmic examinations, (2) eyes with unreadable fundus photographs, aphakic or pseudophakic condition, severe ocular trauma, leucoma, no refraction data, refractive surgery or no visual acuity.

\section{Data collection and examinations}

The study participants underwent a comprehensive examination. The first examination involved the completion of a questionnaire with a series of information, such as age, gender, ethnicity (ie, Han and Uygur), residence (ie, rural and urban), occupations (ie, agricultural work was considered outdoor work, whereas the others were considered indoor work), the level of education (ie, below middle school and high school or higher), history of selfreported clinician-diagnosed hypertension and diabetes, and lifestyle (ie, smoking, drinking, physical work and exercise). Smoking/drinking status was divided into never and ever smokers/drinkers (including current and former smokers/drinkers). Based on the intensity, physical work was classified into light, moderate and heavy. Exercise was divided into never, irregular and regular. Regular exercise was defined as participation in moderate or vigorous activities for $20 \mathrm{~min}$ and above per day at least 3 days a week.

The second examination involved body examination, including the measurement of height $(\mathrm{cm})$ and weight $(\mathrm{kg})$. Body mass index (BMI) was measured in weight $(\mathrm{kg}) /$ height $(\mathrm{m})^{2}$. Systolic blood pressure $(\mathrm{SBP})$ and diastolic blood pressure (DBP) were measured with a digital automatic blood pressure monitor, and the average of three measurements was recorded. Individuals with hypertension were defined as those with a hypertension history or who had SBP $\geq 140 \mathrm{~mm} \mathrm{Hg}$ or DBP $\geq 90 \mathrm{~mm}$ Hg. Diabetes was defined in individuals with self-reported clinician-diagnosed diabetes.

We also performed comprehensive ophthalmological examinations including non-cycloplegic refraction (ARK-510A, Nidek, Tokyo, Japan). SE was calculated as the sphere value plus half of the cylinder value. High myopia, myopia, hyperopia and emmetropia were defined as $\mathrm{SE}<-6.0 \mathrm{D}, \mathrm{SE}<-0.5 \mathrm{D}, \mathrm{SE}>+0.50 \mathrm{D}$ and $\mathrm{SE}$ between $-0.5 \mathrm{D}$ and $+0.5 \mathrm{D}$, respectively. Presenting visual acuity (PVA) was defined in participants wearing habitual optical correction devices (spectacles or contact lenses), if any. The use of portable hand-held slit lamp (KJ5S2, Suzhou Kangjie Medical, Jiangsu, China) and nonmydriatic digital photographs of the fundus (Canon CR2NM2 camera, Canon, Tokyo, Japan) were also recorded. Myopic maculopathy was classified in accordance with META-PM classification. ${ }^{11}$ Myopic maculopathy was divided into five categories: Category 0 (C0), no myopia retinal lesion; Category 1 (C1), tessellated fundus; Category 2 (C2), diffuse chorioretinal atrophy; Category 3 (C3), patchy chorioretinal atrophy; Category 4 (C4), macular atrophy. Three additional features were included in these categories as 'plus signs': lacquer cracks, myopic choroidal neovascularisation (CNV) and Fuchs' spot. Myopic maculopathy was defined as C2 and above and/ or any plus signs. The assessment of myopic maculopathy 
was performed independently by two trained investigators (TC and JM), who were blinded to other information, such as age, gender and SE. Any disagreements were resolved by consensus.

\section{Patient and public involvement}

No patients or members of the public were involved in the design, implementation, reporting or dissemination of our research.

\section{Statistical analysis}

The age-adjusted prevalence of myopic maculopathy was calculated by using the National Census 2010. Frequency data were reported as numbers and percentages, and continuous data were described as mean $\pm \mathrm{SD}$. We explored the associations between the prevalence of myopia maculopathy and the possible risk factors and studied the ethnic differences in Han and Uygur people. The generalised estimating equation (GEE) model for logistic regression analysis was used to assess the relationship between the prevalence of myopic maculopathy and the possible risk factors for eye-specific data in a single person. OR and 95\% CIs were calculated. Visual impairment was assessed using the better eyes of patients. All $p$ values were two sided, and statistical significance was considered at $\mathrm{p}<0.05$. Statistical analysis was performed using SAS software (SAS V.9.3).

\section{RESULTS}

\section{Population characteristics}

Figure 1 shows the workflow of participant inclusion and exclusion criteria. A total of 4023 Han and Uygur participants aged 40 years and older and who completed the questionnaire were considered eligible for the study, and $3339(83.0 \%)$ subjects participated in the ophthalmic examinations. Based on the inclusion and

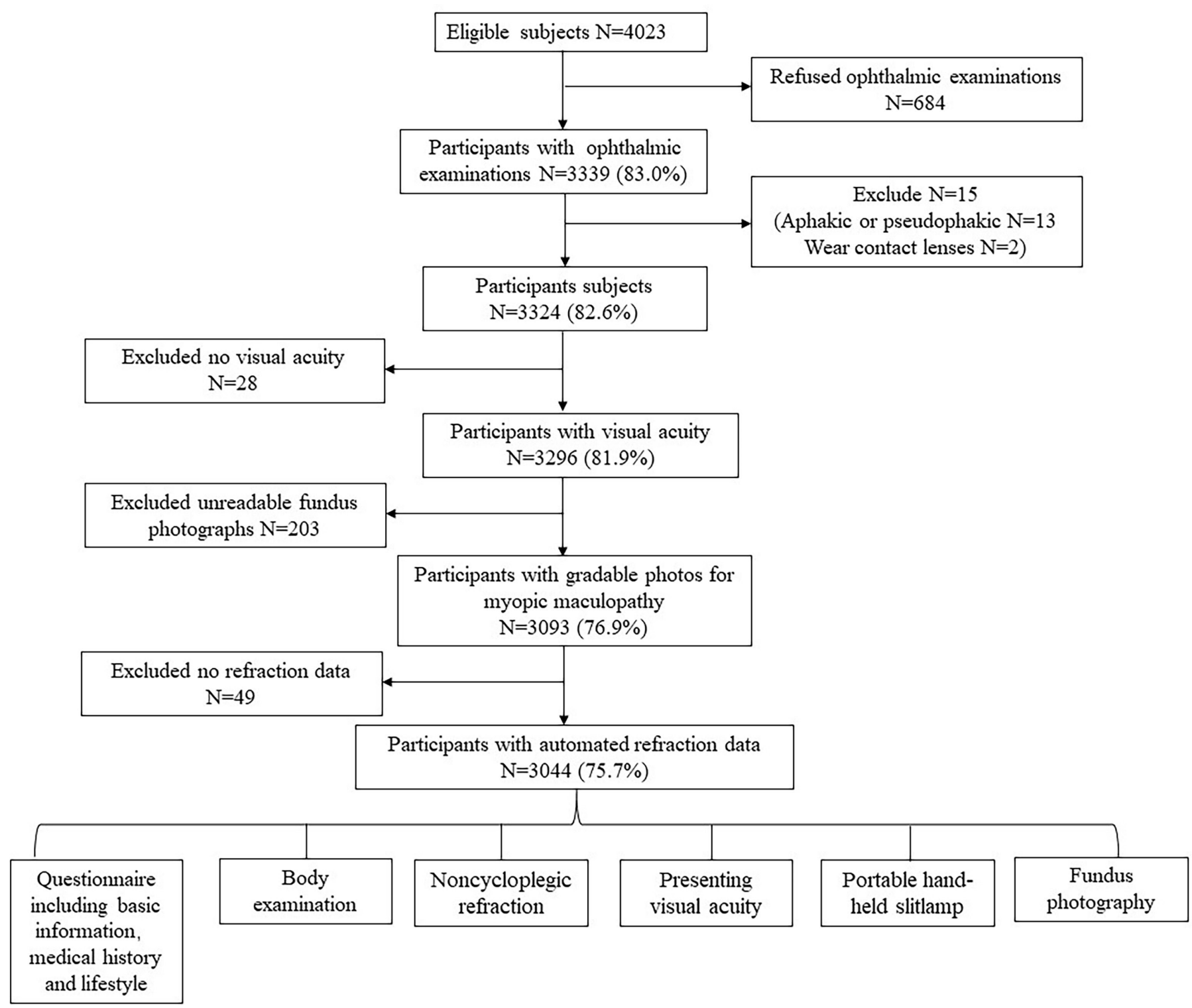

Figure 1 Workflow of participants inclusion and exclusion criteria. 
Table 1 Characteristics of all subjects, adults with and without myopic maculopathy, and Han and Uygur people

\begin{tabular}{|c|c|c|c|c|c|c|c|}
\hline \multirow[b]{2}{*}{ Variables } & \multirow[b]{2}{*}{ All $(n=3044)$} & \multicolumn{3}{|c|}{ Status of myopic maculopathy } & \multicolumn{3}{|c|}{ Ethnicity } \\
\hline & & $\begin{array}{l}\text { Myopic } \\
\text { maculopathy } \\
(n=138)\end{array}$ & $\begin{array}{l}\text { Without } \\
\text { myopic } \\
\text { maculopathy } \\
(n=2906)\end{array}$ & $P$ value & $\operatorname{Han}(n=1736)$ & $\begin{array}{l}\text { Uygur } \\
(n=1308)\end{array}$ & $P$ value \\
\hline Age (years) & $52.2 \pm 9.4$ & $63.2 \pm 10.5$ & $51.7 \pm 9.0$ & $<0.001$ & $53.0 \pm 9.7$ & $51.3 \pm 8.9$ & $<0.001$ \\
\hline Gender & & & & 0.05 & & & 0.14 \\
\hline Male & $1256(41.3 \%)$ & $46(33.3 \%)$ & $1210(41.6 \%)$ & & $736(42.4 \%)$ & $520(39.8 \%)$ & \\
\hline Female & $1788(58.7 \%)$ & $92(66.7 \%)$ & $1696(58.4 \%)$ & & $1000(57.6 \%)$ & $788(60.2 \%)$ & \\
\hline Height (cm) & $161.4 \pm 8.2$ & $158.9 \pm 8.5$ & $161.5 \pm 8.2$ & $<0.001$ & $161.7 \pm 8.1$ & $161.0 \pm 8.4$ & 0.04 \\
\hline Weight $(\mathrm{kg})$ & $66.9 \pm 12.1$ & $63.2 \pm 11.8$ & $67.1 \pm 12.1$ & $<0.001$ & $65.1 \pm 11.5$ & $69.2 \pm 12.5$ & $<0.001$ \\
\hline $\mathrm{BMI}\left(\mathrm{kg} / \mathrm{m}^{2}\right)$ & $25.6 \pm 3.9$ & $25.0 \pm 4.0$ & $25.7 \pm 3.9$ & 0.03 & $24.8 \pm 3.5$ & $26.7 \pm 4.1$ & $<0.001$ \\
\hline SE (D) & $-0.18 \pm 2.31$ & $-5.03 \pm 6.91$ & $-0.01 \pm 1.75$ & $<0.001$ & $-0.46 \pm 2.56$ & $0.20 \pm 1.88$ & $<0.001$ \\
\hline Residence & & & & $<0.001$ & & & $<0.001$ \\
\hline Urban & $1594(52.4 \%)$ & $92(66.7 \%)$ & $1502(51.7 \%)$ & & $989(57.0 \%)$ & $605(46.3 \%)$ & \\
\hline Rural & $1450(47.6 \%)$ & 46 (33.3\%) & $1404(48.3 \%)$ & & $747(43.0 \%)$ & $703(53.8 \%)$ & \\
\hline Education & & & & 0.02 & & & 0.04 \\
\hline $\begin{array}{l}\text { Under middle } \\
\text { school }\end{array}$ & $1718(56.4 \%)$ & $91(65.9 \%)$ & $1627(56.0 \%)$ & & $1008(58.1 \%)$ & $710(54.3 \%)$ & \\
\hline $\begin{array}{l}\text { High school or } \\
\text { higher }\end{array}$ & $1326(43.6 \%)$ & 47 (34.1\%) & 1279 (44.0\%) & & 728 (41.9\%) & $598(45.7 \%)$ & \\
\hline Occupation & & & & $<0.001$ & & & $<0.001$ \\
\hline Outdoor & 1156 (38.3\%) & 29 (21.0\%) & 1136 (39.1\%) & & $618(35.6 \%)$ & 547 (42.8\%) & \\
\hline Indoor & 1879 (61.7\%) & 109 (79.0\%) & 1770 (61.9\%) & & $1118(64.4 \%)$ & $761(58.2 \%)$ & \\
\hline Hypertension & 597 (19.6\%) & 44 (31.9\%) & $553(19.0 \%)$ & $<0.001$ & $371(21.4 \%)$ & $226(17.3 \%)$ & 0.01 \\
\hline Diabetes & 243 (8.0\%) & 18 (13.0\%) & $225(7.7 \%)$ & 0.02 & $146(8.4 \%)$ & 97 (7.4\%) & 0.31 \\
\hline Smoking & & & & 0.09 & & & 0.02 \\
\hline Never & 2094 (68.8\%) & $104(75.4 \%)$ & 1990 (68.5\%) & & $1164(67.1 \%)$ & $930(71.1 \%)$ & \\
\hline Ever & 950 (31.2\%) & 34 (24.6\%) & 916 (31.5\%) & & 572 (33.0\%) & 378 (28.9\%) & \\
\hline Alcohol use & & & & 0.03 & & & $<0.001$ \\
\hline Never & 1853 (60.9\%) & 96 (69.6\%) & 1757 (60.5\%) & & 883 (50.9\%) & $970(74.2 \%)$ & \\
\hline Ever & 1191 (39.1\%) & 42 (30.4\%) & 1149 (39.5\%) & & $853(49.1 \%)$ & 338 (25.8\%) & \\
\hline Exercise & & & & $<0.001$ & & & $<0.001$ \\
\hline Never & 1522 (50.0\%) & 42 (30.4\%) & 1480 (50.9\%) & & 707 (40.7\%) & $815(62.3 \%)$ & \\
\hline Irregular & 492 (16.2\%) & 16 (11.6\%) & 476 (16.4\%) & & 303 (17.5\%) & 189 (14.5\%) & \\
\hline Regular & 1030 (33.8\%) & 80 (58.0\%) & $950(32.7 \%)$ & & $726(41.8 \%)$ & $304(23.2 \%)$ & \\
\hline Physical work & & & & $<0.001$ & & & 0.02 \\
\hline Light & 1707 (56.1\%) & $114(82.6 \%)$ & $1593(54.8 \%)$ & & $1011(58.2 \%)$ & $696(53.2 \%)$ & \\
\hline Moderate & 399 (13.1\%) & $7(5.1 \%)$ & 392 (13.5\%) & & $223(12.9 \%)$ & $176(13.5 \%)$ & \\
\hline Heavy & 938 (30.8\%) & $17(12.3 \%)$ & 921 (31.7\%) & & 502 (28.9\%) & 436 (33.3\%) & \\
\hline
\end{tabular}

BMI, body mass index; SE, spherical equivalent.

exclusion criteria, $3044(75.7 \%)$ participants (5946 eyes) with gradable photos for myopic maculopathy and automated refraction data were included in the final analysis. Table 1 lists the characteristics of all subjects and comparison results between adults with and without myopic maculopathy and between Han and Uygur people. The participants included 1256 (41.3\%) men and $1788(58.7 \%)$ women. A total of $1736(57.0 \%)$ Han and $1308(43.0 \%)$ Uygur individuals were included. The average age of the included population was 52.2 \pm 9.4 years, which is younger than that of non-participants $(54.1 \pm 10.2$ years; $p<0.001)$. Less women and more higher 
Table 2 Distribution of myopic maculopathy in Han and Uygur populations

Category of myopic maculopathy

\begin{tabular}{llllrrrr}
\hline Ethnicity & Numbers & C0 (\%) & C1 (\%) & C2 (\%) & C3 (\%) & \multicolumn{1}{c}{ C4 (\%) } & \multicolumn{1}{c}{$\begin{array}{l}\text { (\%) } \\
\text { (\%) signs }\end{array}$} \\
\hline Han & 1736 & $1638(94.4)$ & $335(19.3)$ & $98(5.6)$ & $17(1.0)$ & $5(0.3)$ & $21(1.2)$ \\
Uygur & 1308 & $1268(96.9)$ & $165(12.6)$ & $41(3.1)$ & $4(0.3)$ & $1(0.1)$ & $4(0.3)$ \\
Total & 3044 & $2906(95.5)$ & $500(16.4)$ & $139(4.6)$ & $21(0.7)$ & $6(0.2)$ & $25(0.8)$ \\
\hline
\end{tabular}

education levels of persons were included $(\mathrm{p}<0.001)$. More Han people were included in participants than in non-participants $(\mathrm{p}=0.04$; see online supplemental file). Han participants were older $(p<0.001)$, had lower BMI $(p<0.001)$ and higher myopic SE $(p<0.001)$ than Uygur participants. The percentiles of rural residents $(p<0.001)$, high level of education $(p=0.04)$, outdoor workers $(\mathrm{p}<0.001)$ and heavy physical workers $(\mathrm{p}=0.02)$ were higher in Uygur than in Han population, whereas the prevalence of hypertension $(p=0.01)$, smoker $(\mathrm{p}=0.02)$, drinkers $(\mathrm{p}<0.001)$ and regularly exercising people $(p<0.001)$ were higher in Han people than in Uygur people. No significant differences were detected in the prevalence of diabetes $(\mathrm{p}=0.31)$ and the distribution of gender $(\mathrm{p}=0.14)$ between Han and Uygur populations. The average SD SE was $-0.18 \pm 2.31 \mathrm{D}$. A total of $458(15.1 \%$; 1092 eyes $(18.4 \%)), 64(2.1 \%$; 177 eyes $(3.0 \%)), 1342(44.1 \% ; 2777$ eyes $(46.7 \%))$ and 1180 $(38.8 \% ; 1900$ eyes $(32.0 \%))$ ) participants were myopic, highly myopic, emmetropic and hyperopic, respectively.

Myopic maculopathy was observed in 198 eyes of 138 participants $(4.5 \%$ of the population), and the ageadjusted prevalence was $5.8 \%$ (95\% CI 4.8 to 6.8 ). The prevalence of myopic maculopathy in Han population $(98,5.7 \%)$ was higher than that in Uygur people (40, $3.1 \% ; \mathrm{p}<0.001)$. Table 2 shows the distribution of myopic maculopathy in Han and Uygur populations. Among the three posterior pole lesions associated with myopic maculopathy, diffuse chorioretinal atrophy was the most common (193 eyes $(3.2 \%)$ or 139 participants $(4.6 \%)$ ), followed by patchy chorioretinal atrophy (28 eyes $(0.5 \%)$ or 21 participants $(0.7 \%))$, whereas macular atrophy had the least percentage ( 7 eyes $(0.1 \%)$ or 6 participants $(0.2 \%))$. Among the 'plus signs', lacquer crack (21 eyes $(0.4 \%)$ or 20 participants $(0.7 \%))$ was the most common, whereas CNV ( 1 eye $(0.02 \%)$ or 1 participant $(0.03 \%)$ ) was the least common. Bilateral myopic maculopathy was present in $57(1.9 \%)$ participants. Figure 2 shows the age-specific and gender-specific prevalence of myopic maculopathy. A significant age-related trend was noted $(p<0.001)$. After adjusting for age, women had a significantly higher prevalence of myopic maculopathy $(5.2 \%)$ than males $(3.7 \%$; $\mathrm{p}=0.02)$. Figure 3 illustrates the prevalence of myopic maculopathy in the high myopic eye obtained by using SE. About 38.8\% participants with SE less than $-6.0 \mathrm{D}$ had myopic maculopathy, and $52.9 \%$ of people with SE less than $-8.0 \mathrm{D}$ had myopic maculopathy.

\section{Univariate analysis of myopic maculopathy}

The univariate analysis showed that high myopic SE $(\mathrm{p}<0.001)$, old age $(\mathrm{p}<0.001)$, low BMI $(\mathrm{p}=0.03)$, urbanisation $(\mathrm{p}<0.001)$, low level of education $(\mathrm{p}=0.02)$, indoor work $(\mathrm{p}<0.001)$, high SBP (myopic maculopathy $(127.7 \pm 16.3 \mathrm{~mm} \mathrm{Hg})$ vs without myopic maculopathy $(122.5 \pm 17.2 \mathrm{~mm} \mathrm{Hg}), \mathrm{p}<0.001)$, diabetes $(\mathrm{p}=0.02)$, nondrinking habit $(\mathrm{p}=0.03)$, status of exercise $(\mathrm{p}<0.001)$ and physical work $(\mathrm{p}<0.001)$ were significantly associated with myopic maculopathy. Gender $(\mathrm{p}=0.05)$, DBP (myopic maculopathy $(75.7 \pm 10.2 \mathrm{~mm} \mathrm{Hg})$ vs without myopic maculopathy $(74.9 \pm 11.3 \mathrm{~mm} \mathrm{Hg}), \mathrm{p}=0.30)$ and smoking $(\mathrm{p}=0.09)$ showed no correlation with myopic maculopathy (table 1). In subjects with myopic maculopathy, in accordance with the WHO definition, $39(41.5 \%)$ and 5 $(5.3 \%)$ participants had visual impairment $(<20 / 60$ to $\geq 20 / 400)$ and blindness $(<20 / 400)$, respectively. Based on the US criteria, legal blindness $(\leq 20 / 200)$ accounted for $14.9 \%$ and visual impairment $(<20 / 40$ to $>20 / 200)$ reached $38.3 \%$.

\section{Multivariate analysis of myopic maculopathy}

In the GEE model, old age (per 1year; OR: 1.16; 95\% CI 1.13 to $1.19 ; \mathrm{p}<0.001$ ) and high myopic SE (per $-1 \mathrm{D}$; OR: $1.48 ; 95 \%$ CI 1.40 to $1.56 ; \mathrm{p}<0.001$ ) were significantly associated with myopic maculopathy. However, ethnicity revealed no association with myopic maculopathy (OR: $0.89 ; 95 \%$ CI 0.53 to $1.48 ; \mathrm{p}=0.64)$. Other factors, such as gender, BMI, residence, level of education, workplace, smoking, alcohol drinking, history of diabetes, DBP, SBP, the type of physical work and exercise, showed

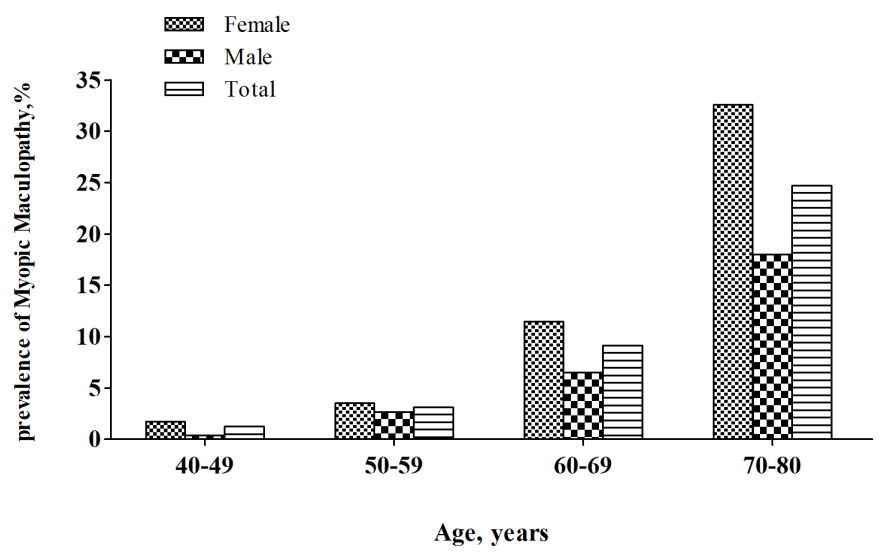

Figure 2 Age-specific and gender-specific prevalence of myopic maculopathy. 


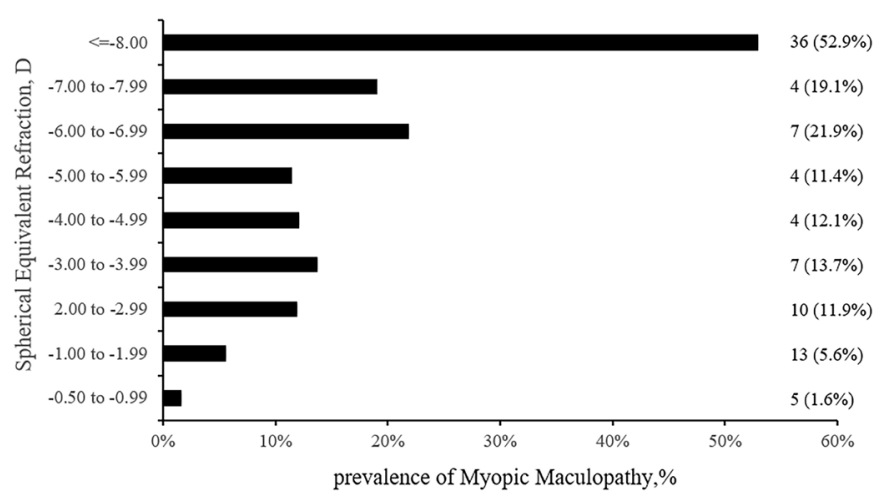

Figure 3 Prevalence of myopic maculopathy in the high myopic eye of participants by spherical equivalent.

no significant association with myopic maculopathy (figure 4).

\section{DISCUSSION}

We performed a cross-sectional study to investigate the prevalence and associated risk factors of myopic maculopathy and to assess whether ethnic differences exist in the distribution of myopic maculopathy between Han and Uygur people living in the same area. The ageadjusted prevalence of myopic maculopathy in our study reached $5.8 \%$. Diffuse chorioretinal atrophy was the most common lesion of myopic maculopathy, and myopic maculopathy was significantly associated with old age and high myopic SE. We found no ethnic differences in the prevalence of myopic maculopathy. Urbanisation, gender and level of education exhibited no association with myopic maculopathy.

The age-adjusted prevalence of myopic maculopathy in our study was higher than the values reported in previous research, such as those of Hisayama Study $(1.7 \%),{ }^{13}$ Beijing Eye Study (BES; 3.1\%), ${ }^{15}$ ShihPai Eye Study
$(3.0 \%),{ }^{12}$ Central India Eye and Medical Study (CIEMS; $0.2 \%)^{16}$ and Handan Eye Study $(1.1 \%)^{17}$ (table 3 ). These differences in the prevalence of myopic maculopathy may be related to the various definitions of myopic maculopathy or distinct study designs or age ranges of these studies. In the present study, we defined myopic maculopathy in accordance with the definition of META-PM, the same as that in CIEMS $^{16}$ and Yangxi Eye Study. ${ }^{18}$ Among these studies, the definition of myopic maculopathy, including the signs such as staphyloma, lacquer cracks, Fuchs' spot and myopic chorioretinal atrophy, was the same in BES ${ }^{15}$ and Blue Mountains Eye Study (BMES). ${ }^{8}$ The reported prevalence values differed. The varied results may be due to the variations in age ranges, residences of participants or other unknown environmental risk factors.

Similar to previous research, ${ }^{13} 1518$ myopic maculopathy in our study increased with advanced age and negative SE. The density of photoreceptors, ganglion cells, retinal pigment epithelium and optic nerve fibres decrease with age. ${ }^{1920}$ Moreover, increasing age is associated with the thin choroid vascular complex ${ }^{21}$ and may compromise blood flow, ${ }^{21}$ which can contribute to the pathogenesis of myopic maculopathy. High myopic SE eyes are usually axially elongated, in which the fundus easily develops pathological changes related to myopic maculopathy. ${ }^{22}$ Studies also showed the strong associations between myopic refractive error, urbanisation and high level of education. ${ }^{23-25}$ Thus, urbanisation and the level of education may have a relationship with myopic maculopathy. In the univariate analysis, urbanisation and the level of education were associated with myopic maculopathy. However, in the multivariate analysis, no significant association was observed between myopic maculopathy and the level of education nor between myopic maculopathy and urbanisation. This phenomenon may due to the effects of urbanisation and education; such effects

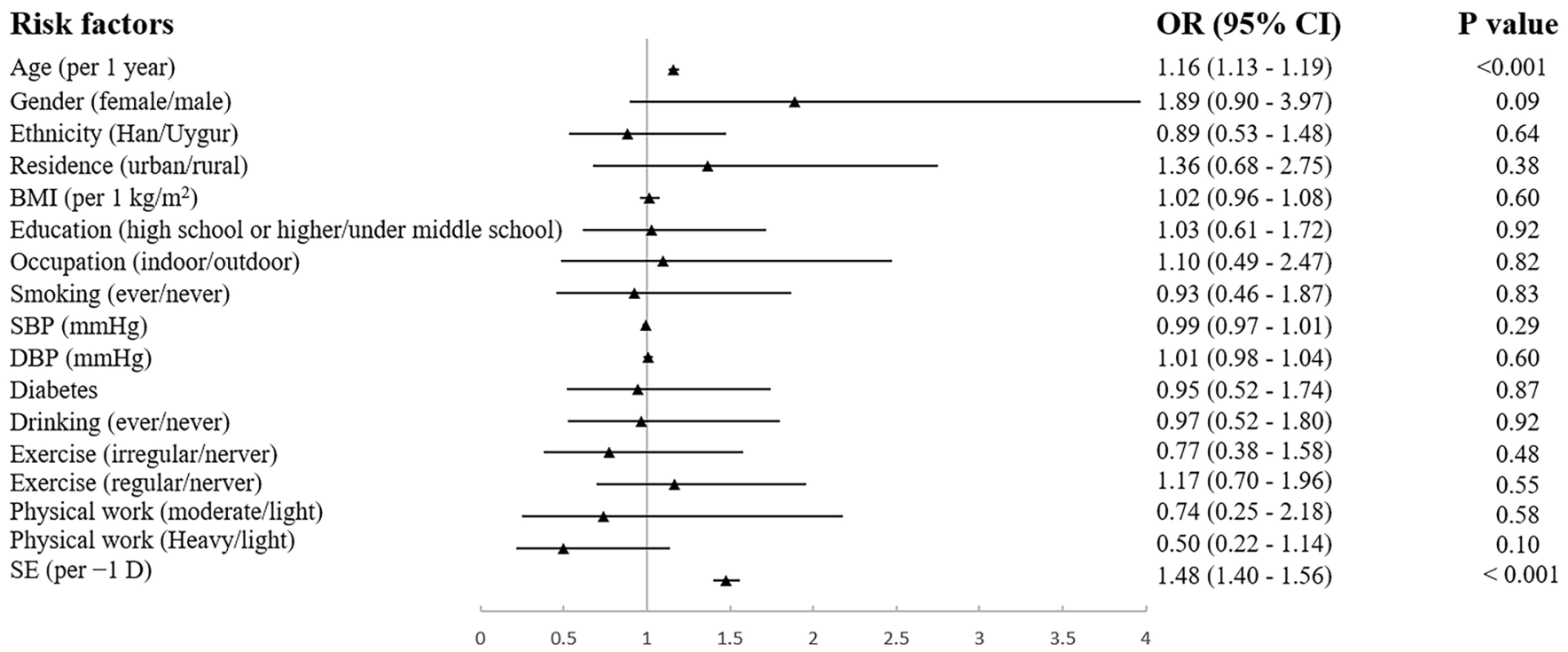

Figure 4 Multivariate analysis of the association between the risk factors and myopic maculopathy. BMI, body mass index; DBP, diastolic blood pressure; SBP, systolic blood pressure; SE, spherical equivalent. 
Table 3 Comparison of prevalence of myopic maculopathy reported in studies

\begin{tabular}{|c|c|c|c|c|c|c|}
\hline Study & Ethnicity & $\begin{array}{l}\text { Examined } \\
\text { year }\end{array}$ & Sample (n) & Age (years) & $\begin{array}{l}\text { Definition of myopic } \\
\text { maculopathy }\end{array}$ & $\begin{array}{l}\text { Prevalence OR, } \\
95 \% \mathrm{Cl}, \%\end{array}$ \\
\hline This current study & Chinese & 2013 & 3044 & $\geq 40$ & $\begin{array}{l}\text { Diffuse chorioretinal } \\
\text { atrophy Patchy } \\
\text { chorioretinal atrophy } \\
\text { Macular atrophy } \\
\text { Lacquer cracks } \\
\text { CNV } \\
\text { Fuchs' spot }\end{array}$ & $\begin{array}{l}5.8 \text { (4.8 to } 6.8) ; \\
\text { age-adjusted }\end{array}$ \\
\hline Hisayama Study ${ }^{13}$ & Southern Japanese & 2005 & 1892 & $\geq 40$ & $\begin{array}{l}\text { Diffuse chorioretinal } \\
\text { atrophy Patchy } \\
\text { chorioretinal atrophy } \\
\text { Lacquer cracks } \\
\text { Macular atrophy }\end{array}$ & 1.7 \\
\hline Shihpai Eye Study ${ }^{12}$ & Chinese & 2000 & 1058 & $\geq 65$ & $\begin{array}{l}\text { Lacquer cracks } \\
\text { Deep choroidal } \\
\text { atrophy } \\
\text { Geographic atrophy } \\
\text { CNV }\end{array}$ & 3.0 (2.1 to 4.2$)$ \\
\hline $\begin{array}{l}\text { Central India } \\
\text { Eye and Medical } \\
\text { Study }^{16}\end{array}$ & $\begin{array}{l}\text { Rural Central } \\
\text { India }\end{array}$ & 2006 & 4561 & $>30$ & $\begin{array}{l}\text { Diffuse chorioretinal } \\
\text { atrophy Patchy } \\
\text { chorioretinal atrophy } \\
\text { Macular atrophy } \\
\text { Lacquer cracks } \\
\text { CNV } \\
\text { Fuchs' spot } \\
\text { Posterior staphyloma }\end{array}$ & $0.2(0.1$ to 0.4$)$ \\
\hline $\begin{array}{l}\text { Handan Eye } \\
\text { Study }^{17}\end{array}$ & $\begin{array}{l}\text { Rural Northern } \\
\text { Chinese }\end{array}$ & 2006-2007 & 6603 & $\geq 30$ & $\begin{array}{l}\text { Staphyloma } \\
\text { Lacquer cracks } \\
\text { Fuchs' spot } \\
\text { Chorioretinal atrophy }\end{array}$ & 0.9 (0.7 to 1.1$)$ \\
\hline
\end{tabular}

CNV, choroidal neovascularisation.

may be explained by the refractive error of the multivariate model, that is, the myopic refractive error indicates the considerable time needed for the development of pathological and anatomical changes associated with myopic maculopathy. During these changes, numerous cofounder factors may exist. For example, urban residences or people with high level of education may pay attention to their eye care, including daily diet, exercise and light work, resulting in the decreased development of myopic maculopathy. Thus, a high degree of myopic refraction was associated with myopic maculopathy, although no association was observed with the level of education or urbanisation.

In the present study, no gender difference was noted in the prevalence of myopic maculopathy, which agrees with result of the Yangxi Eye Study, ${ }^{18}$ Shihpai Eye Study, ${ }^{12}$ Handan Eye Study, ${ }^{17}$ BES $^{15}$ and BMES. ${ }^{8}$ A high prevalence of myopic maculopathy was reported in CIEMS, with a 
257 -fold increased risk observed in women. ${ }^{16}$ We analysed similar results and observed the wide range of the $95 \%$ CI 7.4 to 8973 , implying a lack of reliability. Lin $e t a t^{22}$ also reported a ninefold increased risk in women, but this risk refers to the association between gender and the progression of myopic maculopathy. In Handan Eye Study, ${ }^{17}$ in which the population was almost the same as Lin's study, ${ }^{22}$ gender difference was not observed with myopic maculopathy. Thus, the gender difference in myopic maculopathy should be investigated further.

Although ethnic difference was associated with myopic maculopathy in the univariate analysis, it was no longer a significant risk factor after multivariate adjustment. The Han population was older and had higher myopic SE than the Uygur population. The confounding effect of ethnic difference was adjusted after the analysis using the multivariate model. Thus, in the present study, no ethnic differences existed in the prevalence of myopic maculopathy in Han and Uygur populations.

SBP plays an important role in the diurnal variation of choroidal thickness. ${ }^{26}{ }^{27}$ High SBP may hamper the choroidal circulation and increase the severity of maculopathy. ${ }^{12}$ However, in the present study, we observed no association between SBP and myopic maculopathy, similar to the result of Hsu's study. ${ }^{21}$ Further clinical studies are needed to confirm the relationship between blood pressure and myopic maculopathy.

Myopic maculopathy is the leading and third cause of visual impairment and blindness in Asians over 30 years old and in Europeans over 40 years old, respectively. ${ }^{1} 1028$ Our study showed that $46.8 \%$ (WHO definition) or $53.2 \%$ (US criteria) of participants with myopic maculopathy experienced PVA classified as visual impairment or blindness. The poor visual acuity of people with myopic maculopathy may be due to myopia-associated anatomical changes in the macula or uncorrected myopic refractive error. Among these people, diffuse chorioretinal atrophy is the most common type of myopic maculopathy.

The strengths of our study include the use of the newly developed META-PM classification for myopic maculopathy, analysis of ethnic differences between Han and Uygur people living in the same location, and exploration of the associated risk factors of myopic maculopathy. However, potential limitations of the present study should be mentioned. First, staphyloma as a sign of myopic maculopathy was not evaluated. Thus, the prevalence of myopic maculopathy in the non-stereoscopic fundus photographs might have been underestimated. Second, the association between axial length and myopic maculopathy was not investigated. Although the relationship between refractive error and myopic maculopathy has been studied, and axial length is significantly associated with refractive error, these parameters may be independent risk factors of myopic maculopathy. Third, similar to all other cross-sectional studies, selection bias might have affected several estimates. The non-participants were older, more likely to be women and achieved lower education levels than the participants in our study. This condition may disturb the representativeness of the study population. Given that myopic maculopathy is associated with old age, the prevalence of myopic maculopathy may be underestimated.

\section{CONCLUSION}

In conclusion, a high prevalence of myopic maculopathy was observed in Han and Uygur people in Xinjiang area. Old age and high degree of myopic refraction were important risk factors for myopic maculopathy in the present study. We observed no ethnic differences in myopic maculopathy in Han and Uygur people living in the same area. The negative association between ethnic and myopic maculopathy needs further verification from other studies.

\section{Author affiliations}

${ }^{1}$ Ophthalmology, Renmin Hospital of Wuhan University, Wuhan, China

${ }^{2}$ Ophthalmology, Peking Union Medical College Hospital, Chinese Academy of

Medical Sciences \& Peking Union Medical College, Beijing, China

${ }^{3}$ Epidemiology and Statistics, Institute of Basic Medical Science, Chinese Academy of Medical Sciences \& Peking Union Medical College, Beijing, China

${ }^{4}$ Centre for Disease Control, Xinjiang Uyghur Autonomous Region Centre for Disease Control and Prevention, Xinjiang, China

${ }^{5}$ Ophthalmology, Xin Jiang Uygur Municipal People’s Hospital, Xinjiang, China

${ }^{6}$ College of Public Health, Xinjiang Medical University, Xinjiang, China

Acknowledgements The authors thank the EnPapers copyediting company for help to revise the language in this manuscript.

Contributors TC designed, collected, analysed the data, and wrote and revised the manuscript. JM and $\mathrm{YZ}$ designed the study, helped in preparing the manuscript, and revised the manuscript. GLS supervised data collection and analyzed the data. LZP, LD, LP, LK, HM, SY, NT, FD and KW were responsible for data collection. All authors provided substantial contributions to the interpretation of the data and provided final approval of manuscript submission.

Funding This work was supported by the National Science \& Technology Pillar Programme during the 12th Five-year Plan Period (2012BAl37B02).

Competing interests None declared.

Patient consent for publication Not required.

Ethics approval Our study was conducted in accordance with the tenets of Declaration of Helsinki. The ethics approval was obtained from the bioethical committee of the Institute of Basic Medical Sciences, the Chinese Academy of Medical Sciences. Written informed consent was obtained from each participant after the nature and possible consequences of the study were explained.

Provenance and peer review Not commissioned; externally peer reviewed.

Data availability statement Data are available upon reasonable request.

This content has been supplied by the author(s). It has not been vetted by BMJ Publishing Group Limited (BMJ) and may not have been peer-reviewed. Any opinions or recommendations discussed are solely those of the author(s) and are not endorsed by BMJ. BMJ disclaims all liability and responsibility arising from any reliance placed on the content. Where the content includes any translated material, BMJ does not warrant the accuracy and reliability of the translations (including but not limited to local regulations, clinical guidelines, terminology, drug names and drug dosages), and is not responsible for any error and/or omissions arising from translation and adaptation or otherwise.

Open access This is an open access article distributed in accordance with the Creative Commons Attribution Non Commercial (CC BY-NC 4.0) license, which permits others to distribute, remix, adapt, build upon this work non-commercially, and license their derivative works on different terms, provided the original work is properly cited, appropriate credit is given, any changes made indicated, and the use is non-commercial. See: http://creativecommons.org/licenses/by-nc/4.0/.

ORCID iDs 
Ting Chen http://orcid.org/0000-0001-7203-1752

Fen Dong http://orcid.org/0000-0003-4761-0239

Yong Zhong http://orcid.org/0000-0002-9511-4726

\section{REFERENCES}

1 Liang YB, Wong TY, Sun LP, et al. Refractive errors in a rura Chinese adult population the Handan eye study. Ophthalmology 2009;116:2119-27.

2 Nangia V, Jonas JB, Sinha A, et al. Refractive error in central India: the central India eye and medical study. Ophthalmology 2010;117:693-9.

3 Sawada A, Tomidokoro A, Araie M, et al. Refractive errors in an elderly Japanese population: the Tajimi study. Ophthalmology 2008;115:363-70.

4 Wolfram C, Höhn R, Kottler U, et al. Prevalence of refractive errors in the European adult population: the Gutenberg health study (GHS). $\mathrm{Br}$ J Ophthalmol 2014;98:857-61.

5 Saw S-M, Gazzard G, Shih-Yen EC, et al. Myopia and associated pathological complications. Ophthalmic Physiol Opt 2005;25:381-91.

6 Morgan IG, Ohno-Matsui K, Saw S-M. Myopia. Lancet 2012;379:1739-48.

7 Hayashi K, Ohno-Matsui K, Shimada N, et al. Long-Term pattern of progression of myopic maculopathy: a natural history study. Ophthalmology 2010;117:1595-611.

8 Vongphanit J, Mitchell P, Wang JJ. Prevalence and progression of myopic retinopathy in an older population. Ophthalmology 2002;109:704-11.

$9 \mathrm{Xu}$ L, Wang Y, Li Y, et al. Causes of blindness and visual impairment in urban and rural areas in Beijing. Ophthalmology 2006;113:1134. e1-1134.e11.

10 Iwase A, Araie M, Tomidokoro A, et al. Prevalence and causes of low vision and blindness in a Japanese adult population: the Tajimi study. Ophthalmology 2006;113:1354-62.

11 Ohno-Matsui K, Kawasaki R, Jonas JB, et al. International photographic classification and grading system for myopic maculopathy. Am J Ophthalmol 2015;159:877-83.

12 Chen S-J, Cheng C-Y, Li A-F, et al. Prevalence and associated risk factors of myopic maculopathy in elderly Chinese: the Shihpai eye study. Invest Ophthalmol Vis Sci 2012;53:4868-73.

13 Asakuma T, Yasuda M, Ninomiya T, et al. Prevalence and risk factors for myopic retinopathy in a Japanese population: the Hisayama study. Ophthalmology 2012;119:1760-5.
$14 \mathrm{He} \mathrm{H}$, Pan L, Pa L, et al. Data resource profile: the China National health survey (CNHS). Int J Epidemiol 2018;47:1734-5.

$15 \mathrm{Liu} \mathrm{HH}$, Xu L, Wang YX, et al. Prevalence and progression of myopic retinopathy in Chinese adults: the Beijing eye study. Ophthalmology 2010;117:1763-8.

16 Jonas JB, Nangia V, Gupta R, et al. Prevalence of myopic retinopathy in rural central India. Acta Ophthalmol 2017;95:e399-404.

17 Gao LQ, Liu W, Liang YB, et al. Prevalence and characteristics of myopic retinopathy in a rural Chinese adult population: the Handan eye study. Arch Ophthalmol 2011;129:1199-204.

18 Li Z, Liu R, Jin G, et al. Prevalence and risk factors of myopic maculopathy in rural southern China: the Yangxi eye study. $\mathrm{Br} J$ Ophthalmol 2019;103:1797-802.

19 Panda-Jonas S, Jonas JB, Jakobczyk-Zmija M. Retinal photoreceptor density decreases with age. Ophthalmology 1995;102:1853-9.

20 Gao H, Hollyfield JG. Aging of the human retina. Differential loss of neurons and retinal pigment epithelial cells. Invest Ophthalmol Vis Sci 1992;33:1-17.

21 Hsu C-C, Chen S-J, Li A-F, et al. Systolic blood pressure, choroidal thickness, and axial length in patients with myopic maculopathy. $J$ Chin Med Assoc 2014;77:487-91.

22 Lin C, Li S-M, Ohno-Matsui K, et al. Five-Year incidence and progression of myopic maculopathy in a rural Chinese adult population: the Handan eye study. Ophthalmic Physiol Opt 2018;38:337-45.

23 Mirshahi A, Ponto KA, Hoehn R, et al. Myopia and level of education: results from the Gutenberg health study. Ophthalmology 2014;121:2047-52.

24 Kim EC, Morgan IG, Kakizaki H, et al. Prevalence and risk factors for refractive errors: Korean National health and nutrition examination survey 2008-2011. PLoS One 2013;8:e80361.

25 Lee JH, Jee D, Kwon J-W, et al. Prevalence and risk factors for myopia in a rural Korean population. Invest Ophthalmol Vis Sci 2013:54:5466-71.

26 Tan CS, Ouyang Y, Ruiz H, et al. Diurnal variation of choroidal thickness in normal, healthy subjects measured by spectral domain optical coherence tomography. Invest Ophthalmol Vis Sci 2012;53:261-6.

27 Usui S, Ikuno Y, Akiba M, et al. Circadian changes in subfoveal choroidal thickness and the relationship with circulatory factors in healthy subjects. Invest Ophthalmol Vis Sci 2012:53:2300-7.

28 Wong Y-L, Saw S-M. Epidemiology of pathologic myopia in Asia and worldwide. Asia Pac J Ophthalmol 2016;5:394-402. 